\section{Analisis KePUASAN PENgguna JaSA TerhadaP KinerJa Konsultan PengaWas Pada PeKerJaAn Konstruksi di Kota Ternate}

\author{
Delailah Abas a, Edward Rizky Ahadian, Muhammad Taufiq Yuda Saputrac \\ abcUniversitas Khairun, Ternate, Indonesia
}

\author{
Article history \\ Received \\ 18 Agusrtus 2021 \\ Received in revised form \\ 5 September 2021 \\ Accepted \\ 20 Oktober 2021 \\ *Corresponding author \\ edward.rizky@unkhair.ac.id
}

\section{Graphical abstract}

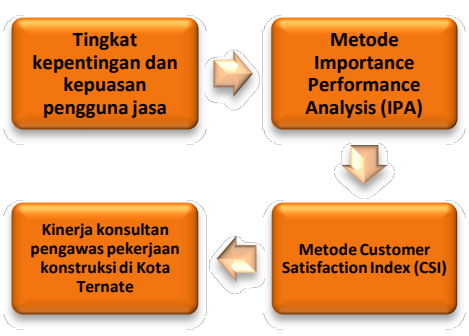

\begin{abstract}
Supervisory consultant is one example of a company that offers services in the production process. The services offered by the supervisory consultants are not always assessed for quality from the final product, namely in the form of a supervisory report, but also from the supervision process during the implementation period. Customers in this context are parties who use products, in the form of services, offered by supervisory consultants. The customer as the party who will enjoy and pay for the final result of the supervisory consultant service process, of course has his own point of view on something that will be paid later. This study aims to determine the important factors and the level of satisfaction of service users (Owner) on the performance of construction work supervisory consultants in Ternate City. Data analysis was carried out using the Customer Satisfaction Index (CSI) method and the Importance Performance Analysis (IPA) method. Based on the IPA method, there are 4 (four) variables in quadrant I. This shows that these variables are considered important by the respondents, but their performance is still felt to be lacking and needs to be improved, namely leading regular meetings in planning and solving problems in the field, compiling reports and minutes in the context of progress of work and payment of installments for construction work, preventing, reducing, or overcoming any problems/complaints from parties outside the project (eg community protests due to noise during the construction process), and each individual involved as a supervisory consultant team is an expert in their field. For the CSI method, a satisfaction index of $83.10 \%$ is obtained, which is included in the "very satisfied" category.
\end{abstract}

Keywords: Supervisory consultant, importance performance analysis, customer satisfaction index.

\begin{abstract}
Abstrak
Konsultan pengawas adalah salah satu contoh perusahaan yang menawarkan jasa dalam proses produksinya. Jasa yang ditawarkan konsultan pengawas tidak selalu dinilai kualitasnya dari hasil akhir produk, yakni berupa laporan pengawasan, namun juga dari proses pengawasan selama jangka waktu pelaksanaan. Pelanggan dalam konteks ini adalah pihak yang menggunakan produk, berupa jasa, yang ditawarkan oleh konsultan pengawas. Pelanggan sebagai pihak yang akan menikmati dan yang membayar hasil akhir dari proses pelayanan konsultan pengawas, tentu memiliki sudut pandangnya sendiri akan sesuatu yang akan dibayarkan nantinya. Penelitian ini bertujuan untuk mengetahui faktor-faktor penting dan tingkat kepuasan pengguna jasa (Owner) terhadap kinerja konsultan pengawas pekerjaan konstruksi di Kota Ternate. Analisis data dilakukan dengan metode Customer Satisfaction Index(CSI) dan metode Importance Performance Analysis(IPA). Berdasarkan metode IPA, terdapat 4 (empat) variabel yang terdapat di kuadran I. Hal ini menunjukkan bahwa variabel-variabel ini dianggap penting oleh para responden, namun kinerjanya masih dirasakan kurang dan perlu ditingkatkan lagi, yaitu memimpin rapat-rapat rutin dalam merencanakan dan menyelesaikan masalah di lapangan, menyusun laporan dan berita acara dalam rangka kemajuan pekerjaan dan pembayaran angsuran pekerjaan pelaksanaan konstruksi, mencegah, mengurangi, atau mengatasi setiap masalah/komplain dari pihak-pihak di luar proyek (contoh : protes masyarakat akibat kebisingan saat proses konstruksi), dan setiap Individu yang terlibat sebagai tim konsultan pengawas adalah ahli pada bidangnya.Untuk metode CSI didapatkan indeks kepuasan sebesar $83,10 \%$ yaitu termasuk dalam kategori "sangat puas".
\end{abstract}

Kata kunci:Konsultan pengawas, importance performance analysis, customer satisfaction index. (C) 2021 Penerbit Fakultas Teknik Unkhair. All rights reserved 


\subsection{PENDAHULUAN}

Konsultan pengawas adalah salah satu contoh perusahaan yang menawarkan jasa dalam proses produksinya. Jasa yang ditawarkan konsultan pengawas tidak selalu dinilai kualitasnya dari hasil akhir produk, yakni berupa laporan pengawasan, namun juga dari proses pengawasan selama jangka waktu pelaksanaan. Pelanggan dalam konteks ini adalah pihak yang menggunakan produk, berupa jasa, yang ditawarkan oleh konsultan pengawas. Pelanggan sebagai pihak yang akan menikmati dan yang membayar hasil akhir dari proses pelayanan konsultan pengawas, tentu memiliki sudut pandangnya sendiri akan sesuatu yang akan dibayarkan nantinya.

Pertimbangan-pertimbangan yang dilakukan pelanggan ini akan selalu mencari nilai yang paling tinggi dari beberapa pilihan jasa yang ada, mereka akan membentuk harapan tentang nilai yang akan diperoleh (value expectation), sehingga dari nilai yang timbul akan menentukan tingkat kepuasan pelanggan terhadap kinerja konsultan pengawas.

\section{Importance Performance Analysis (IPA)}

IPA menggabungkan pengukuran faktor tingkat kepentingan dan tingkat kepuasan dalam grafik dua dimensi yang memudahkan penjelasan data dan mendapatkan usulan praktis. Interpretasi grafik IPA sangat mudah, dimana grafik IPA dibagi menjadi empat buah kuadran berdasarkan hasil pengukuran importanceperformance. Data yang digunakan untuk analisis ini adalah hasil kuesioner persepsi pengguna jasa terhadap kinerja konsultan pengawas suatu berdasarkan indikator penilaian yang telah ditetapkan. Analisis Kuadran ini berfungsi untuk memetakan kinerja dan kepentingan (harapan) dari pengguna jasa terhadap beberapa indikator kualitas pelayanan yang mempengaruhi kepuasan pelanggan.

Dalam penelitian ini terdapat dua variabel yang digunakan yaitu tingkat kinerja pelayanan yang dialami dan dinyatakan dengan $\mathrm{X}$, serta tingkat harapan dinyatakan dengan $\mathrm{Y}$.

Rumus yang digunakan (Supranto, 1993) adalah sebagai berikut :

$$
\mathrm{Tki}=\frac{\mathrm{Xi}}{\mathrm{Yi}} \times 100 \%
$$

Keterangan :

Tki $=$ Tingkat kesesuaian responden

$X i=$ Jumlah Skor penilaian tingkat keterlibatan pada setiap variabel

$Y_{i}=$ Jumlah Skor penilaian tingkat kepentingan pada setiap variabel

Selanjutnya sumbu mendatar (X) akan diisi oleh skor tingkat kinerja sedangkan sumbu vertikal (Y) akan diisi oleh skor tingkat kepentingan/harapan. Untuk setiap faktor yang mempengaruhi penilaian pengguna jasa dengan menggunakan rumus:

$$
\begin{aligned}
& \bar{X}=\frac{\sum x i}{n} \\
& \bar{Y}=\frac{\sum y i}{n}
\end{aligned}
$$

Keterangan :

$\mathrm{X}^{-}=$Skor rata-rata tingkat keterlibatan pada setiap variabel

$\mathrm{Y}^{-}=$Skor rata-rata tingkat kepentingan pada setiap variabel

$\mathrm{n}=$ Jumlah Responden

Selanjutnya adalah menghitung rata-rata tingkat kepentingan dan kinerja untuk keseluruhan indikator, dengan rumus :

$$
\begin{aligned}
& \bar{X}=\frac{\sum x i}{k} \\
& \bar{Y}=\frac{\sum y i}{k}
\end{aligned}
$$

Keterangan :

$\mathrm{X}^{-}=$Batas rata-rata skor tingkat pelaksanaan atau keterlibatan Konsultan pengawas

$\mathrm{Y}^{-}=$Batas Rata-rata skor tingkat kepentingan Konsultan pengawas

$\mathrm{k}=$ Jumlah variabel yang diujikan 


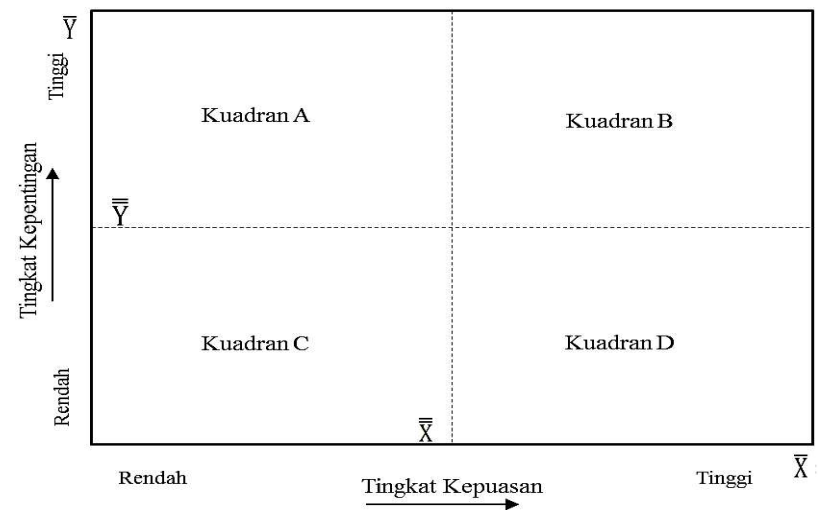

Gambar 1.MatriksImportance-Performance (Sumber: Risya, 2013)

\section{Metode Customer Satisfaction Index}

Customer Satisfaction Index (CSI) digunakan untuk mengetahui tingkat kepuasan pengguna jasa secara menyeluruh dengan melihat tingkat kinerja dan tingkat kepentingan/harapan dari atribut-atribut jasa pelayanan. Menurut Aritonang (2005), untuk mengetahui besarnya nilai CSI, maka langkah-langkah yang dilakukan yaitu :

Menentukan Mean Importance Score (MIS) atau rata-rata skor kepentingan. Nilai ini diperoleh dari rata-rata tingkat kepentingan/ harapan pengguna jasa.

$$
\mathrm{MIS}=\frac{\left.\llbracket \sum_{\mathrm{i}=1}^{\mathrm{n}} \mathrm{Yi}_{\mathrm{i}}\right]}{\mathrm{n}}
$$

Keterangan:

$Y i=$ Nilai kepentingan atribut $\mathrm{Y}$ ke-i

$n=$ Jumlah responden

Menghitung Weight Faktor (WF) atau faktor tertimbang. Bobot ini merupakan persentase nilai MIS per indikator terhadap total MIS seluruh indikator.

$$
\mathrm{WF}=\frac{\mathrm{MISi}}{\sum_{\mathrm{i}=1}^{\mathrm{p}} \mathrm{MISi}} \times 100 \%
$$

Keterangan:

MISi = Nilai rata-rata kepentingan ke-i

$\sum_{i=1}^{\mathrm{p}} \mathrm{MISi}=$ Total rata-rata kepentingan dari ke-i ke-p

Menghitung Weight Score (WS) atau Skor tertimbang. Bobot ini merupakan perkalian antara WF dengan rata-rata tingkat kinerja (Mean Performance Score = MPS)

$$
\mathrm{WSi}=\mathrm{WFi} \times \mathrm{M} \text { PS }
$$

Keterangan:

$\mathrm{WFi}=$ Faktor tertimbang ke-i

MPS = Rata-rata tingkat kepuasan

Menentukan Customer Satisfaction Index (CSI)

$$
\mathrm{CSI}=\frac{\sum_{\mathrm{i}=1}^{\mathrm{p}} \mathrm{WSi}}{\mathrm{HS}} \times 100 \%
$$


Keterangan:

$\sum_{i=1}^{\mathrm{p}} \mathrm{WSi}=$ Total rata-rata skor kepentingan dari-i ke-p

HS = HS (higest scale) merupakan skala maksimum yang digunakan

Bila nilai CSI $>50 \%$ maka dapat dikatakan bahwa pengguna jasa telah merasa puas, sebaliknya bila CSI < $50 \%$ maka pengguna jasa belum merasa puas. Nilai CSI dalam penelitian ini dibagi dalam lima kriteria dari tidak puas sampai dengan sangat puas.

\subsection{METODE PENELITIAN}

Lokasi penelitian bertempat di 6 Instansi yaitu Universitas Khairun Ternate, Poltekes Ternate, Universitas IAIN ternate, Balai Pelaksanaan Jalan Nasional Maluku Utara, Balai Prasana Pemukiman Maluku Utara, dan Dinas Pekerjaan Umum Kota Ternate.

\subsection{Rancangan Kuesioner}

Kuesioner dibuat untuk mengukur secara langsung tingkat kepentingan dan kepuasan pelanggan terhadap kinerja konsultan pengawas di Kota Ternate. Tingkat kepuasan menggambarkan tingkat perasaan pelanggan terhadap kinerja pelayanan atau produk yang diterimanya. Sedangkan tingkat kepentingan menggambarkan hal-hal yang dianggap penting oleh pelanggan atau dapat dikatakan sebagai harapan dari pelanggan. Untuk tingkat kepentingan dan kepuasan dari penilaian responden diberikan skor penilaian menggunakan skala likert dengan nilai 1 sampai dengan 5. Berikut adalah variabel pengukuran kinerja konsultan pengawas yang selanjutnya akan digunakan sebagai pertanyaan dalam penyebaran kuisioner penelitian ini.

Tabel 1. Kriteria-kriteria pengukuran kinerja konsultan pengawas

\begin{tabular}{|c|c|}
\hline Indikator & Variabel \\
\hline \multirow[t]{5}{*}{$\begin{array}{l}\text { Kemampuan Mencapai } \\
\text { Tujuan Proyek }\end{array}$} & $\begin{array}{l}\text { V.1. Melakukan pengendalian dan pengawasan terhadap penggunaan sumber daya } \\
\text { tenaga kerja, bahan/material, peralatan dan biaya }\end{array}$ \\
\hline & V.2. Mengendalikan dan memastikan proyek tepat waktu (sesuai dengan rencana) \\
\hline & V.3 Mengendalikan dan memastikan proyek tepat biaya (sesuai dengan rencana) \\
\hline & $\begin{array}{l}\text { V.4 Melakukan pemeriksaan, koreksi, dan persetujuan terhadap setiap pelaksanaan } \\
\text { pekerjaan (shop drawings) yang diajukan pelaksana konstruksi }\end{array}$ \\
\hline & $\begin{array}{l}\text { V.5 Melakukan pengawasan pada pelaksanaan pekerjaan agar sesuai dengan } \\
\text { spesifikasi }\end{array}$ \\
\hline \multirow{5}{*}{$\begin{array}{l}\text { Kemampuan } \\
\text { Manajerial } \\
\text { Proyek }\end{array}$} & $\begin{array}{l}\text { V.6. Menerangkan batasan kerja, ruang lingkup pekerjaan, dan spesifikasi dengan } \\
\text { baik kepada semua stakeholder proyek }\end{array}$ \\
\hline & V.7. Melakukan koordinasi terhadap semua stakeholder yang terlibat dalam proyek \\
\hline & $\begin{array}{l}\text { V.8. Memimpin rapat-rapat rutin dalam merencanakan dan menyelesaikan masalah } \\
\text { di lapangan }\end{array}$ \\
\hline & $\begin{array}{l}\text { V.9. Secara berkala membuat laporan/ monitoring \& evaluasi terhadap kemajuan } \\
\text { pelaksanaan pekerjaan }\end{array}$ \\
\hline & $\begin{array}{l}\text { V.10.Menyusun laporan dan berita acara dalam rangka kemajuan pekerjaan dan } \\
\text { pembayaran angsuran pekerjaan pelaksanaan konstruksi }\end{array}$ \\
\hline \multirow{4}{*}{$\begin{array}{l}\text { Kemampuan Menjamin } \\
\text { Dan Menambah Mutu } \\
\text { Pekerjaan }\end{array}$} & $\begin{array}{l}\text { V.11.Memberikan rekomendasi perubahan ruang lingkup (bahan/ material, maupun } \\
\text { metode pelaksanaan) yang lebih baik jika diperlukan }\end{array}$ \\
\hline & $\begin{array}{l}\text { V.12.Memberikan pelayanan konsultasi setiap saat (selama proyek berlangsung) } \\
\text { kepada seluruh stakeholder proyek }\end{array}$ \\
\hline & $\begin{array}{l}\text { V.13.Melakukan pemeriksaan terhadap kualitas hasil pekerjaan agar sesuai dengan } \\
\text { spesifikasi }\end{array}$ \\
\hline & V.14.Mendeteksi dan memberikan koreksi terhadap defect/ cacat \\
\hline \multirow{2}{*}{$\begin{array}{l}\text { Kemampuan mencegah, } \\
\text { mengurangi, atau } \\
\text { mengatasi masalah / }\end{array}$} & $\begin{array}{l}\text { V.15.Mengendalikan penerapan Sistem Manajemen Kesehatan dan Keselamatan } \\
\text { Kerja SMK3 pada proyek dengan baik }\end{array}$ \\
\hline & V.16.Mencegah, mengurangi, atau mengatasi setiap masalah-masalah yang ada di \\
\hline
\end{tabular}




\begin{tabular}{ll}
\hline \multicolumn{1}{c}{ Indikator } & \multicolumn{1}{c}{ Variabel } \\
\hline konflik & dalam proyek \\
\cline { 2 - 2 } & $\begin{array}{l}\text { V.17.Mencegah, mengurangi, atau mengatasi setiap masalah/ komplain dari } \\
\text { pihakpihak di luar proyek (contoh : protes masyarakat akibat kebisingan saat proses } \\
\text { konstruksi) }\end{array}$ \\
\cline { 2 - 2 } & $\begin{array}{l}\text { V.18.Memahami dan dapat menyampaikan kebutuhan dan keinginan owner dengan } \\
\text { cepat dan tepat }\end{array}$ \\
\hline $\begin{array}{l}\text { Kualitas } \\
\text { Internal SDM } \\
\text { Konsultan } \\
\text { Pengawas }\end{array}$ & $\begin{array}{l}\text { V.19.Setiap Individu yang terlibat sebagai tim Konsultan pengawas adalah ahli pada } \\
\text { bidangnya }\end{array}$ \\
\cline { 2 - 2 } & V.20.Memahami secara komperhensif dokumen untuk pelaksanaan konstruksi \\
\cline { 2 - 2 } & V.21.Kooperatif dalam setiap tindakan dan pengambilan keputusan \\
\hline
\end{tabular}

\subsection{HASIL DAN PEMBAHASAN}

\subsection{Importance Perfomance Analysis (IPA)}

Dalam metode Importance Performance Analysis (IPA) ini, kemudian dilakukan perhitungan selanjutnya yaitu perhitungan nilai tingkat kepentingan/harapan dan tingkat kepuasan pengguna jasa konsultan pengawas. Kemudian menghitung rata-rata tingkat kepuasan $(\mathrm{X})$ dan rata-rata tingkat kepentingan (Y) dan kemudianhasilnya akan dipetakan ke dalam diagram kartesius yang terbagi dalam 4 kuadran dengan menggunakan bantuan software SPSS 16.0 for Windows.

Tabel 2.Hasil Perhitungan Rata-Rata Seluruh Variabel

\begin{tabular}{cccccc}
\hline No & Variabel & Tingkat kepuasan $(\mathbf{X})$ & Tingkat kepentingan $(\mathbf{Y})$ & Rata-rata $(\mathbf{X})$ & Rata-rata $(\mathbf{Y})$ \\
\hline 1 & V1 & 85 & 93 & 4,05 & 4,43 \\
\hline 2 & V2 & 89 & 99 & 4,24 & 4,71 \\
\hline 3 & V3 & 82 & 92 & 3,90 & 4,38 \\
\hline 4 & V4 & 86 & 93 & 4,10 & 4,43 \\
\hline 5 & V5 & 92 & 94 & 4,38 & 4,48 \\
\hline 6 & V6 & 86 & 92 & 4.10 & 4,38 \\
\hline 7 & V7 & 87 & 93 & 4,14 & 4,43 \\
\hline 8 & V8 & 87 & 95 & 4,14 & 4,52 \\
\hline 9 & V9 & 92 & 96 & 4,38 & 4,57 \\
\hline 10 & V10 & 87 & 97 & 4,14 & 4,62 \\
\hline 11 & V11 & 85 & 86 & 4,05 & 4,10 \\
\hline 12 & V12 & 90 & 90 & 4,29 & 4,29 \\
\hline 13 & V13 & 86 & 87 & 4,10 & 4,14 \\
\hline 14 & V14 & 86 & 93 & 4,10 & 4,33 \\
\hline 15 & V15 & 86 & 91 & 4,29 & 4,43 \\
\hline 16 & V16 & 90 & 93 & 4,00 & 4,48 \\
\hline 17 & V17 & 84 & 94 & 4,38 \\
\hline 18 & V18 & 84 & 92 & & \\
\hline & & & & 400 & \\
\hline
\end{tabular}




\begin{tabular}{cccccc}
\hline No & Variabel & Tingkat kepuasan $(\mathbf{X})$ & Tingkat kepentingan $(\mathbf{Y})$ & Rata-rata $(\mathbf{X})$ & Rata-rata (Y) \\
\hline 19 & V19 & 86 & 97 & 4,10 & 4,62 \\
\hline 20 & V20 & 88 & 98 & 4,19 & 4,67 \\
\hline 21 & V21 & 87 & 93 & 4,14 & 4,43 \\
\hline 22 & V22 & 91 & 95 & 4,33 & 4,52 \\
\hline Total & 91,38 & 97,76 & & &
\end{tabular}

\subsection{Diagram Kartesius Per Variabel}

Untuk menentukan perpotongan dari dua buah garis yang tegak lurus $(\mathrm{X})$ dan $(\mathrm{Y})$ sebagai pembagian daerah dengan menggunakan persamaan (4) dan (5).

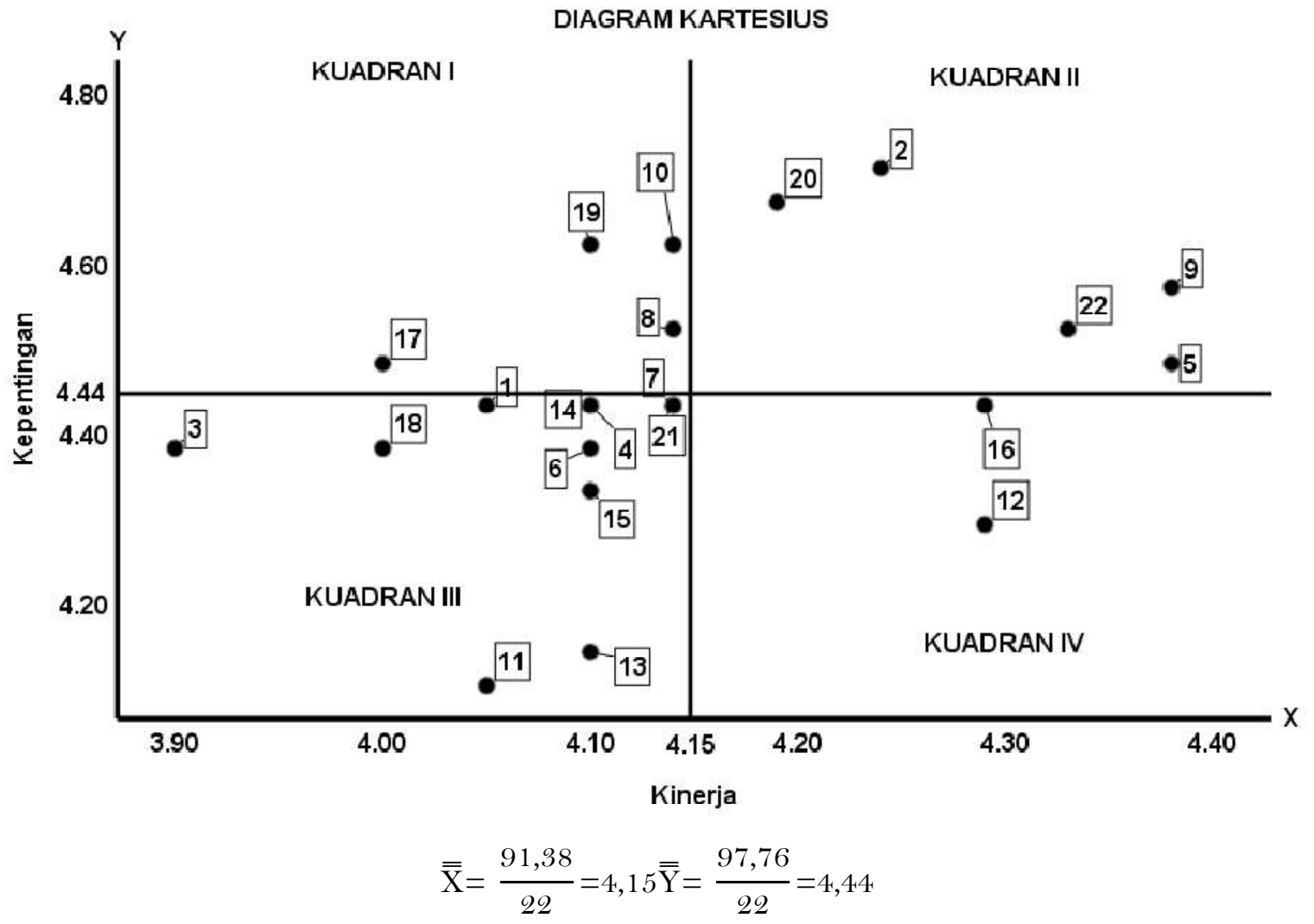

Gambar 2. Diagram Kartesius Seluruh Variabel

Setelah dilakukan perhitungan dengan metode Importance Performance Analysis (IPA) menggunakan SPSS, didapatkan hasil dari setiap kuadran pada diagram Kartesius. Dari gambar diagram 2 dapat dilihat bahwa penilaian dari pengguna jasa Konsultan pengawas di Kota Ternate mengenai tingkat kinerja dan tingkat kepentingan terhadap kinerja konsultan pengawas tersebar di 4 kuadran yaitu sebagai berikut :

a. Kuadran I (focus improvement).

Menunjukan variabel-variabel yang mempengaruhi kinerja konsultan pengawas. yang berada dalam kuadran ini dalam penanganannya perlu untuk diprioritaskan atua ditingkatkan, karena keberadaan variabel-variabel inilah yang dinilai sangat penting oleh pengguna jasa, sedangkan tingkat pelaksanaannya masih belum memuaskan.

Dilihat dari gambar diagram 2 bahwa variabel yang termasuk dalam kuadran I adalah:

1. V.8. Memimpin rapat-rapat rutin dalam merencanakan dan menyelesaikan masalah di lapangan 
2. V.10.Menyusun laporan dan berita acara dalam rangka kemajuan pekerjaan dan pembayaran angsuran pekerjaan pelaksanaan konstruksi

3. V.17.Mencegah, mengurangi, atau mengatasi setiap masalah/ komplain dari pihakpihak di luar proyek (contoh : protes masyarakat akibat kebisingan saat proses konstruksi)

4. V.19.Setiap Individu yang terlibat sebagai tim Konsultan pengawas adalah ahli pada bidangnya

b. Kuadran II (maintain performance).

Menunjukan variabel-variabel yang mempengaruhi kinerja konsultan pengawas. yang berada dalam kuadran ini dalam penanganannya perlu untuk dipertahankan kinerjanya, karena pada umumnya tingkat pelaksanaanya telah sesuai dengan kepentingan dan harapan pengguna jasa, sehingga kepuasan dari pengguna jasa telah tercapai.

Dilihat dari gambar diagram 4.5 bahwa variable yang termasuk dalam kuadran II adalah :

1. V.2. Mengendalikan dan memastikan proyek tepat waktu (sesuai dengan rencana)

2. V.5 Melakukan pengawasan pada pelaksanaan pekerjaan agar sesuai dengan spesifikasi

3. V.9. Secara berkala membuat laporan/ monitoring \& evaluasi terhadap kemajuan pelaksanaan pekerjaan

4. V.20.Memahami secara komperhensif dokumen untuk pelaksanaan konstruksi

5. V.22.Terbuka dan menerima masukan yang konstrukstif

c. Kuadran III (medium low priority).

Menunjukan variabel-variabel yang mempengaruhi kinerja konsultan pengawas. yang berada dalam kuadran ini dinilai masih dianggap kurang penting bagi pengguna jasa, sedangkan kualitas pelaksanaanya biasa atau cukup saja, dalam penanganannya tidak perlu diprioritaskan atau ditingkatkan dan termasuk prioritas rendah.

Dilihat dari gambar diagram 4.5 bahwa variabel yang termasuk dalam kuadran III adalah:

1. V.1.Melakukan pengendalian dan pengawasan terhadap penggunaan sumber daya : tenaga kerja, bahan/material, peralatan dan biaya

2. V.3 Mengendalikan dan memastikan proyek tepat biaya (sesuai dengan rencana)

3. V.4 Melakukan pemeriksaan, koreksi, dan persetujuan terhadap setiap pelaksanaan pekerjaan (shop drawings) yang diajukan pelaksana konstruksi

4. V.6.Menerangkan batasan kerja, ruang lingkup pekerjaan, dan spesifikasi dengan baik kepada semua stakeholder proyek

5. V.7.Melakukan koordinasi terhadap semua stakeholder yang terlibat dalam proyek

6. V.11.Memberikan rekomendasi perubahan ruang lingkup (bahan/ material, maupun metode pelaksanaan) yang lebih baik jika diperlukan

7. V.13.Melakukan pemeriksaan terhadap kualitas hasil pekerjaan agar sesuai dengan spesifikasi

8. V.14.Mendeteksi dan memberikan koreksi terhadap defect/ cacat pada hasil pekerjaan

9. V.15.Mengendalikan penerapan Sistem Manajemen Kesehatan dan Keselamatan Kerja SMK3 pada proyek dengan baik

10. V.18.Memahami dan dapat menyampaikan kebutuhan dan keinginan owner dengan cepat dan tepat

11. V.21.Kooperatif dalam setiap tindakan dan pengambilan keputusan

\section{d. Kuadran IV (reduce emphasis).}

Menunjukan variabel-variabel yang mempengaruhi kinerja konsultan pengawas yang berada dalam kuadran ini dinilai berlebihan dalam pelaksanaanya, hal ini terutama disebabkan karena pengguna jasa menganggap tidak terlalu penting terhadap adanya variabel tersebut, sedang kualitas pelaksanaanya sangat baik sehingga sangat memuaskan.

Dilihat dari gambar diagram 4.5 bahwa variabel yang termasuk dalam kuadran IV adalah :

1. V.12.Memberikan pelayanan konsultasi setiap saat (selama proyek berlangsung) kepada seluruh stakeholder proyek

2. V.16.Mencegah, mengurangi, atau mengatasi setiap masalah-masalah yang ada di dalam proyek

\subsection{Customer Satisfaction Index (CSI)}

Customer Satisfaction Index (CSI) dapat digunakan untuk mengukur kepuasan pelanggan secara keseluruhan (Aritonang, 2005). Sedangkan menurut Irawan (2002), pengukuran terhadap Customer Satisfaction Index (CSI) diperlukan karena hasil dari pengukuran dapat digunakan sebagai acuan untuk menentukan sasaran-sasaran di tahun-tahun mendatang. Indeks kepuasan pelanggan (CSI) dapat dihitung dengan tahapan yang pertama yaitu 
menentukan Mode Importance Score (MIS), kemudian menentukan Weight Factor(WF), lalu menentukan Mode Satisfaction Score (MSS) pada tiap atribut, kemudian membuat Weight Score (WS) dan yang terakhir menghitung

Tabel 3.Customer Satisfaction Index (CSI).

\begin{tabular}{|c|c|c|c|c|c|c|c|}
\hline \multirow{2}{*}{ No } & \multirow{2}{*}{ Variabel } & \multicolumn{2}{|c|}{ Tingkat Kepentingan (Y) } & \multicolumn{2}{|c|}{ Tingkat Kepuasan (X) } & \multirow{2}{*}{ WF } & \multirow{2}{*}{ WS } \\
\hline & & Jumlah nilai $Y$ & Nilai MIS & Jumlah nilai $\mathrm{X}$ & Nilai MSS & & \\
\hline 1 & V1 & 93 & 4.43 & 85 & 4.05 & 4.53 & 18.34 \\
\hline 2 & $\mathrm{~V} 2$ & 99 & 4.71 & 89 & 4.24 & 4.82 & 20.44 \\
\hline 3 & V3 & 92 & 4.38 & 82 & 3.90 & 4.48 & 17.50 \\
\hline 4 & $\mathrm{~V} 4$ & 93 & 4.43 & 89 & 4.24 & 4.53 & 19.20 \\
\hline 5 & $\mathrm{~V} 5$ & 94 & 4.48 & 92 & 4.38 & 4.58 & 20.06 \\
\hline 6 & V6 & 92 & 4.38 & 86 & 4.10 & 4.48 & 18.35 \\
\hline 7 & V7 & 93 & 4.43 & 87 & 4.14 & 4.53 & 18.77 \\
\hline 8 & V8 & 95 & 4.52 & 87 & 4.14 & 4.63 & 19.17 \\
\hline 9 & V9 & 96 & 4.57 & 92 & 4.38 & 4.68 & 20.49 \\
\hline 10 & V10 & 97 & 4.62 & 87 & 4.14 & 4.72 & 19.57 \\
\hline 11 & V11 & 86 & 4.10 & 85 & 4.05 & 4.19 & 16.96 \\
\hline 12 & V12 & 90 & 4.29 & 90 & 4.29 & 4.38 & 18.79 \\
\hline 13 & V13 & 87 & 4.14 & 86 & 4.10 & 4.24 & 17.35 \\
\hline 14 & V14 & 93 & 4.43 & 86 & 4.10 & 4.53 & 18.55 \\
\hline 15 & V15 & 91 & 4.33 & 86 & 4.10 & 4.43 & 18.15 \\
\hline 16 & V16 & 93 & 4.43 & 90 & 4.29 & 4.53 & 19.41 \\
\hline 17 & $\mathrm{~V} 17$ & 94 & 4.48 & 84 & 4.00 & 4.58 & 18.31 \\
\hline 18 & V18 & 92 & 4.38 & 84 & 4.00 & 4.48 & 17.92 \\
\hline 19 & V19 & 97 & 4.62 & 86 & 4.10 & 4.72 & 19.35 \\
\hline 20 & $\mathrm{~V} 2 \mathrm{O}$ & 98 & 4.67 & 88 & 4.19 & 4.77 & 20.00 \\
\hline 21 & $\mathrm{~V} 21$ & 93 & 4.43 & 87 & 4.14 & 4.53 & 18.77 \\
\hline 22 & $\mathrm{~V} 22$ & 95 & 4.52 & 91 & 4.33 & 4.63 & 20.05 \\
\hline CSI & & & & $3,10 \%$ & & & \\
\hline
\end{tabular}

- Menentukan Customer Satisfaction Index (CSI), membagi weighted total dengan skala nominal yang digunakan kemudian dikalikan 100 persen. Dengan menggunakan rumus no 9), diperoleh hasil sebagai berikut:

$$
\mathrm{CSI}=\frac{415.50}{5} \times 100 \%=83,10 \%
$$

Dimana :

$\mathrm{P}=$ jumlah atribut kepentingan

$5=$ jumlah skala

Berdasarkan perhitungan CSI di atas dapat diketahui bahwa indeks kepuasan pengguna jasa terhadap kinerja yang diberikan oleh Konsultan pengawas mendapatkan nilai sebesar 83,10\%. Hal ini menunjukkan bahwa tingkat kepuasan pengguna jasa berada pada kategori "Sangat Puas”.

Tabel 4. Customer Satisfaction Index Interpretation

\begin{tabular}{cc}
\hline Angka Indeks & Interpretasi \\
\hline $80 \%<$ Satisfaction index $\leq 100 \%$ & Sangat puas \\
\hline $60 \%<$ Satisfaction index $\leq 80 \%$ & Puas \\
\hline $40 \%<$ Satisfaction index $\leq 60 \%$ & Cukup puas \\
\hline
\end{tabular}




\begin{tabular}{cc}
\hline $20 \%<$ Satisfaction index $\leq 40 \%$ & Tidak puas \\
\hline $0 \%<$ Satisfaction index $\leq 20 \%$ & Sangat tidak puas \\
\hline
\end{tabular}

\subsection{KESIMPULAN}

Berdasarkan hasil penelitian yang telah dilakukan di 6 instansi di Kota ternate yaitu Universitas Khairun Ternate, Poltekes Ternate, Universitas IAIN ternate, Balai Pelaksanaan Jalan Nasional Maluku Utara, Balai Prasana Pemukiman Maluku Utara, dan Dinas Pekerjaan Umum Kota Ternate. maka didapatkan kesimpulan sebagai berikut :

1. Berdasarkan analisa metode Importance Performance Analysis (IPA) memperlihatkan ada 4 (empat) variabel yang terdapat di kuadran I. Hal ini menunjukkan bahwa variabel-variabel ini dianggap penting oleh para responden, namun kinerjanya masih dirasakan kurang dan perlu ditingkatkan.Variabel tersebut adalah 1 . memimpin rapat-rapat rutin dalam merencanakan dan menyelesaikan masalah di lapangan,2. menyusun laporan dan berita acara dalam rangka kemajuan pekerjaan dan pembayaran angsuran pekerjaan pelaksanaan konstruksi,3. mencegah, mengurangi, atau mengatasi setiap masalah/ komplain dari pihakpihak di luar proyek (contoh : protes masyarakat akibat kebisingan saat proses konstruksi),4.Setiap Individu yang terlibat sebagai tim Konsultan pengawas adalah ahli pada bidangnya.

2. Dari perhitungan dengan menggunakan metode Customer Satisfaction Index (CSI) diperoleh nilai indeks kepuasan sebesar $83,10 \%$. Nilai tersebut termasuk dalam kategori "sangat puas". Hal tersebut menunjukkan bahwa pengguna jasa sangat puas dengan kinerja yang telah diberikan oleh Konultan pengawas. Namun masih terdapat variabel-variabel yang perlu dilakukan perbaikan.

\section{Ucapan Terima Kasih}

Ucapan terima kasih disampaikan kepada semua pihak yang telah berperan dalam penelitian analisis kepuasan pengguna jasa terhadap kinerja konsultan pengawas pada pekerjaan konstruksi di kota Ternatesehingga penelitian ini dapat di selesaikan dengan baik.

\section{References}

[1] Armstrong dan Kotler. 1996. Dasar-Dasar Pemasaran. Jakarta : Intermedia.

Band, O. 1991. Membangun Kepuasan Pelanggan. Jakarta: Gramedia Pustaka Utama. Husnaini. 2001. Manajemen. Jakarta : Bumi Aksara

Khasani, Riqi Radian. 2013. Evaluasi kepuasan pelanggan terhadap kinerja manajemen proyek kontraktor besar bangunan gedung. 136. http://eprints.undip.ac.id/39977/1/Tesis_Riqi_Radian_K.pdf Juran 1993. Quality Planning and Analysis, 3rd Edition. MC-Graw Hill Book Inc. New York Maloney WF.2002.Construction product/service and customer satisfaction. ASCE:Journal of Construction Engineering and Management.

[10] Mathis, Robert L, dan H. Jackson. 2006. Manajemen Sumber Daya Manusia. Alih Bahasa Jimmy Sadeli. Penerbit Salemba Empat: Jakarta

[11] Oggi Rahmat Asfary. 2018 Analisis Kepuasan Pelanggan Menggunakan Pendekatan Importance Performance Analysis Dan Customer Satisfaction Index

[12] Oliver, Riscrd L, (1997), Satisfaction A Behavioral Perspective On The Consumer. McGraw-Hill Education, Singapore.

[13] Rust, R. T. dan Oliver, R. L. 1994 . Service Quality New DirectionIn Theory And Practice.Sage. California

[14] Sedarmayanti. 2001. Sumber Daya Manusia dan Produktivitas Kerja. Mnadar Maju.

[15] Siagian. 2003, Manajemen Sumber Daya Manusia edisi satu, cetakan kesepuluh. Jakarta : Bumi Aksara. 
[16] Sinungan, Muchdarsyah. 2005. Produktivitas. Jakarta : Bumi Aksara

[17] Sumaga, A. 2013. Analisis Kepuasan Pengguna Jasa Terhadap Penerapan Manajemen Rekayasa Konstruksi Profesional Ruko Di Kawasan Bussiness Park Kota Gorontalo. Jurnal Ilmiah Media Engineering, 3(1), 99768.

[18] Sugiyono. 2011. Metode Penelitian Kuantitatif, Kualitatif dan R\&D. Bandung: Afabeta

[19] Tse dan Wilton 1988. Kepuasan Pelanggan, jilid 2. Edisi ketiga. Klaten : PT. Indeks Kelompok Gramedia.

[20] Tjiptono. 2011. Service Management Mewujudkan Layanan Prima.

[21] Umam, R. K., \& Hariastuti, N. P. 2018. Analisis kepuasan pelanggan dengan menggunakan metode Customer Satisfaction Index (CSI) dan Importance Performance Analysis (IPA). Seminar Nasional Sains Dan Teknologi Terapan, 339-344. 